\title{
Prostaglandin-induced Abortion: Assessment of Operative Complications and Early Morbidity
}

\author{
I. Z. MACKENZIE, KEITH HILLIER, M. P. EMBREY
}

British Medical fournal, 1974, 4, 683-686

\section{Summary}

A total of 626 patients undergoing a prostaglandininduced abortion, the majority in the second trimester, have been analysed for complications occurring during inpatient treatment. Of the last 155 consecutive patients 143 were critically assessed six to eight weeks after abortion for morbidity occurring during their early recovery period.

Blood loss of $250 \mathrm{ml}$ or more occurred in 68 patients, pyrexia in 34, pelvic infection in three, and readmission in 14 of the 626 patients studied, and a transfusion was required in eight.

Bleeding after abortion stopped within six weeks in all 143 of the 155 consecutive patients assessed but three required readmission for uterine curettage. Menstruation was re-established within six weeks of abortion in 106 patients.

The incidence of operative morbidity was similar to that reported for first trimester abortion and better than that in most reported series of second trimester abortions.

\section{Introduction}

Several critical analyses have been published recently of the risks associated with termination of pregnancy (Kerslake and Casey, 1967; Loung et al., 1971; Sood, 1971; Stallworthy et al., 1971; Beric et al., 1973).

Prostaglandins have achieved an accepted place in the management of mid-trimester pregnancy termination. At present in Great Britain the use of these agents is restricted to intravenous or extra-amniotic administration, and the intraamniotic route is permitted for investigational use in certain centres. We report here on an analysis of the immediate morbidity associated with abortion induced by the intra- or extra-amniotic administration of prostaglandin $\mathrm{F}_{2} \alpha\left(\mathrm{PGF}_{2} \alpha\right)$ or prostaglandin $E_{2}\left(P_{G E}\right)$ in 626 patients and on the results of critical prospective assessment six weeks after abortion in 143 patients. These results form part of a survey still in progress.

\section{General Features}

Since 1970 more than 700 abortions have been performed with prostaglandins in this unit. During the 12 months ending December 1973 they were used in $95 \%$ of mid-trimester abortions, which accounted for $24 \%$ of all terminations performed in Oxford. The initial months after the introduction of prostaglandins in 1970 were devoted to investigation of different doses and routes of administration including intravenous and

Nuffield Department of Obstetrics and Gynaecology, John Radcliffe Hospital, Oxford

I. Z. MACKENZIE, M.B., M.R.C.o.G., Research Fellow

KEITH HILLIER, B.SC., PH.D., Research Fellow

M. P. EMBREY, F.R.C.S., F.R.C.O.G., Clinical Reader in Obstetrics and Gynaecology vaginal administration as well as intra- and extra-amniotic techniques. With the two former routes numbers were small and in some instances documentation incomplete, and, additionally, intravenous and vaginal administration were found to be unacceptable for routine use (Hillier and Embrey, 1972, and unpublished data). Such cases together with those of patients with missed abortion or hydatidiform moles were therefore excluded from the study, leaving 626 cases for detailed analysis.

Outpatient clinic appointments were arranged for all patients six weeks after abortion, but many defaulted and examination of the records showed that observations made were often inadequate. In view of this a prospective, and still continuing, survey of patients has been performed in the last eight months with one doctor examining all patients.

The age and marital status of all patients are shown in table $I$. At the time of abortion 336 patients had had no previous pregnancies, 67 had had one, 83 had had two, 59 had had three, 38 had had four, 24 had had five, and 19 had had six or more. Gestation is charted in relation to the route of prostaglandin administration in table II.

\section{PATIENT MANAGEMENT}

Abortions were induced using extra-amniotic or intra-amniotic administration of prostaglandins (table III). The techniques of administration were standard but with increasing experience the dose and frequency of administration were altered, resulting in a reduction in abortion times. Extra-amniotic administration was performed as described by Embrey et al. (1972). In most cases intermittent extra-amniotic injections of $200 \mu \mathrm{g} \mathrm{PGE}_{2}$ every two hours (total dose $450-7,650 \mu \mathrm{g}$ ) or $750 \mu \mathrm{g} \mathrm{PGF}_{2} \alpha$ every two hours (total dose $1,750-30,000 \mu \mathrm{g}$ ) were given. In the last eight months of the study 75 patients were given only two injections (500 $\mu \mathrm{g}-1,500 \mu \mathrm{gGE}_{2}$ ) with an interval of six to 12 hours between them. Altogether $66 \%$ of the 530 patients given extra-amniotic prostaglandin received adjunctive intravenous oxytocin $(80 \mathrm{mU} / \mathrm{min})$ starting four hours after the initial prostaglandin injection. Intra-amniotic administration (total dosage $\mathrm{PGE}_{2} 10-20 \mathrm{mg}, \mathrm{PGF}_{2} \propto 25-50 \mathrm{mg}$ ) was described by MacKenzie et al. (1974). Adjunctive oxytocin therapy $(80 \mathrm{mU} /$ min) was given to compliment uterine activity (Embrey et al., 1973; MacKenzie et al., 1974) in 50\% of these patients.

Vital signs and side effects were recorded on specific data sheets. Pyrexia was classified as a temperature over $38^{\circ} \mathrm{C}$ on at least one occasion. Antibiotics were given after collection of specimens for bacteriological culture if infection was clinically suspected. Hypotension was classified as a fall of systolic blood pressure of at least $20 \mathrm{~mm} \mathrm{Hg}$, and blood loss was considered excessive if greater than $250 \mathrm{ml}$. Blood transfusions were given when clinically indicated. Unit policy regarding management of cases immediately after abortion has varied. Initially, only patients with clinically incomplete abortions underwent evacuation, but later a policy of routine evacuation for all patients was adopted. Greater experience of prostaglandin administration and the application of different dose schedules resulted, however, in a high incidence of complete abortion and 
TABLE I-Age and Marital Status of 626 Women who Underwent Prostaglandin-induced Abortion. Results are Numbers of Patients

\begin{tabular}{|c|c|c|c|c|c|c|c|c|}
\hline Age in Years: & $<16$ & $16-19$ & $20-24$ & $25-29$ & $30-34$ & $35-39$ & $40-45$ & Total (\%) \\
\hline $\begin{array}{l}\text { Single } \\
\text { Married } \\
\text { Separated or divorced }\end{array}$ & 63 & $\begin{array}{r}185 \\
8\end{array}$ & $\begin{array}{r}103 \\
45 \\
1\end{array}$ & $\begin{array}{r}29 \\
49 \\
9\end{array}$ & $\begin{array}{r}3 \\
52 \\
3\end{array}$ & $\begin{array}{r}47 \\
1\end{array}$ & $\begin{array}{r}26 \\
2\end{array}$ & $\begin{array}{c}383(61 \cdot 2) \\
227(36 \cdot 3) \\
16(2 \cdot 6)\end{array}$ \\
\hline Total (\%) & $63(10 \cdot 1)$ & $193(30 \cdot 8)$ & $149(23 \cdot 8)$ & $87(13.9)$ & $58(9 \cdot 3)$ & $48(7 \cdot 7)$ & $28(4 \cdot 5)$ & $626(100)$ \\
\hline
\end{tabular}

TABLE II-Gestation and Route of Prostaglandin Administration in 626 Women. Results are Numbers of Patients

\begin{tabular}{|c|c|c|c|c|c|c|c|c|c|}
\hline & Weeks: & $<9$ & $9-12$ & $13-14$ & $15-16$ & $17-18$ & $19-20$ & $21-22$ & $>22$ \\
\hline $\begin{array}{l}\text { Extra-amniotic } \\
\text { Intra-amniotic }\end{array}$ & & 8 & 24 & 113 & $\begin{array}{r}199 \\
17\end{array}$ & $\begin{array}{r}120 \\
38\end{array}$ & $\begin{array}{l}42 \\
28\end{array}$ & $\begin{array}{l}21 \\
12\end{array}$ & $\begin{array}{l}3 \\
1\end{array}$ \\
\hline & Total $(\%)$ & $8(1 \cdot 3)$ & $24(3 \cdot 8)$ & $113(18 \cdot 1)$ & $216(34 \cdot 5)$ & $158(25 \cdot 2)$ & $70(11 \cdot 2)$ & $33(5 \cdot 3)$ & $4(0 \cdot 6)$ \\
\hline
\end{tabular}

TABLE III-Abortion Times in 626 Women according to Prostaglandin Used and Route of Administration

\begin{tabular}{l|c|c|c|c}
\hline & Prostaglandin $\mathrm{E}_{2}$ & \multicolumn{2}{|c|}{ Prostaglandin $\mathrm{F}_{2} \alpha$} \\
\cline { 2 - 4 } & $\begin{array}{c}\text { No. of } \\
\text { Patients }\end{array}$ & $\begin{array}{c}\text { Mean (Range) } \\
\text { Abortion Time } \\
\text { (Hours) }\end{array}$ & $\begin{array}{c}\text { No. of } \\
\text { Patients }\end{array}$ & $\begin{array}{c}\text { Mean (Range) } \\
\text { Abortion Time } \\
\text { (Hours) }\end{array}$ \\
\hline $\begin{array}{l}\text { Extra-amniotic } \\
\text { Intra-amniotic }\end{array}$ & 438 & $\begin{array}{c}16 \cdot 7(3-82) \\
17 \cdot 2(5-73)\end{array}$ & 22 & $\begin{array}{c}\mathbf{2 5} \cdot 1 \text { (4-68) } \\
37 \cdot 3(5-72)\end{array}$ \\
\hline
\end{tabular}

reversion to a conservative policy. All patients were examined bimanually before discharge from hospital.

Rhesus-negative patients routinely received anti-D $\gamma$-globulin during the first 24 hours after abortion unless scheduled for tubal ligation.

\section{Inpatient Observations}

\section{MORBIDITY}

The commonest side effects were gastrointestinal. Altogether 291 $(46.5 \%)$ patients vomited on at least one occasion, the incidence being greater in patients treated intra-amniotically $(54.2 \%)$ than extra-amniotically (34\%). Twenty-eight patients had one or more episodes of diarrhoea, which was also more common with intra-amniotic treatment. The incidence of these side effects was similar with $\mathrm{PGF}_{2} \alpha$ and $\mathrm{PGE}_{2}$ treatment.

Pyrexia was observed in 34 patients, 12 of whom were given antibiotics. One patient treated with intra-amniotic $\mathrm{PGE}_{2}$ developed a pyrexia with a rigor and another treated with $\mathrm{PGE}_{2}$ developed a Gram-negative septicemia, but both recovered uneventfully with antibiotic therapy. One patient, apyrexic while in hospital, subsequently developed pelvic sepsis. Transient hypotension was noted in 25 patients after the initial injection of prostaglandin but no specific therapy was necessary. Two patients developed a transient bronchospasm after the start of extra-amniotic $\mathrm{PGF}_{2} \alpha$ but neither needed treatment. No convulsive episodes were recorded during treatment though eight patients were epileptics receiving anticonvulsant therapy.

Surgical evacuation was performed on 278 patients $(44.4 \%)$. On the conservative policy of the last eight months of the study, however, 33 out of $113(29 \cdot 2 \%)$ extra-amniotic patients and seven out of $42(16.7 \%)$ intra-amniotic patients underwent evacuation. More recent experience with modified managment indicates that this number may be reduced further without added complication (unpublished data).

Clinically estimated blood loss of $250 \mathrm{ml}$ or more was recorded in 68 patients $(10.8 \%)$-in $9 \%$ of cases up to 12 weeks gestation, $12 \%$ from 13 and 16 weeks gestation, and $10 \%$ at 17 weeks and over. Thirty-eight patients $(6 \cdot 1 \%)$ lost over $500 \mathrm{ml}$ and one patient lost 1,500 ml. Eight patients needed a blood transfusion. The route of administration did not influence the degree of blood loss.

Three patients sustained lacerations to the cervix. In only one, treated with intra-amniotic $\mathrm{PGE}_{2}$, was suturing of a posterior lip laceration necessary. No other genital tract trauma was detected. Altogether 14 of the 626 patients were readmitted because of excessive vaginal bleeding in 13 and pelvic infection in one.

\section{DURATION OF STAY}

The improvement in abortion time with altered treatment schedules and the reduction in the number of patients requiring evacuation during the last eight months of the study period resulted in an increase in patients discharged within 24 hours from $15 \cdot 9 \%$ to $58 \cdot 1 \%$ (table IV).

\section{Short-term Follow-up}

Of the last 155 consecutive patients $143(92 \cdot 3 \%)$ were interviewed and examined by one doctor six to eight weeks after abortion. All had been terminated with $\mathrm{PGE}_{2}, 101$ by the extra-amniotic route and 42 by the intra-amniotic route. Thirty-eight patients ( 31 extra-amniotic and seven intraamniotic) required surgical evacuation for incomplete expulsion and four other patients had a curettage at elective tubal ligation within 24 hours of complete abortion. Five patients, three of whom needed antibiotics, were pyrexic during the abortion process. Four patients lost more than $250 \mathrm{ml}$ blood and one of these needed transfusion.

TABLE IV-Duration of Hospitalization in Patients not Undergoing Tubal Ligation and Number Undergoing Ligation in Two Periods. Results are Number (\%) of Patients in each Period

\begin{tabular}{|c|c|c|c|c|c|c|c|}
\hline & \multicolumn{5}{|c|}{ No. of Days in Hospital } & \multirow{2}{*}{$\begin{array}{c}\text { Patients under- } \\
\text { going Tubal } \\
\text { Ligation }\end{array}$} & \multirow{2}{*}{ Total } \\
\hline & 1 & 2 & 3 & 4 & 5 & & \\
\hline $\begin{array}{l}\text { July 1973 } \\
\text { i.ugust 1973-March } 1974\end{array}$ & $\begin{array}{l}75(15 \cdot 9) \\
90(58 \cdot 1)\end{array}$ & $\begin{array}{r}254(53 \cdot 9) \\
50(32 \cdot 3)\end{array}$ & $\begin{array}{l}91(19 \cdot 3) \\
7(4 \cdot 5)\end{array}$ & $\begin{array}{r}24(5 \cdot 1) \\
1(0 \cdot 6) \\
\end{array}$ & $\begin{array}{r}16(3 \cdot 4) \\
2(1 \cdot 3) \\
\end{array}$ & $\begin{array}{r}11(2 \cdot 3) \\
5(3 \cdot 2)\end{array}$ & $\begin{array}{l}471 \\
155\end{array}$ \\
\hline Total & $165(26 \cdot 3)$ & $304(48 \cdot 6)$ & $98(15 \cdot 7)$ & $25(4 \cdot 0)$ & $18(2 \cdot 9)$ & $16(2 \cdot 6)$ & 626 \\
\hline
\end{tabular}


TABLE V-Duration of Vaginal Bleeding and Onset of Menstruation in 143 Patients after Abortion

\begin{tabular}{l|c|c|c|c|c|c|}
\hline & \multicolumn{3}{|c|}{ Duration of Vaginal Blood Loss (Weeks) } & \multicolumn{2}{|c|}{ Onset of Menstruation (Weeks) } \\
\cline { 2 - 5 } No. (\%) of patients & $<1$ & $1-2$ & -3 & -6 & $<3$ \\
\hline $11(7 \cdot 7)$ & $75(52 \cdot 5)$ & $32(22 \cdot 4)$ & $25(17 \cdot 5)$ & $3-4$ \\
\hline
\end{tabular}

\section{DURATION OF VAGINAL BLEEDING AND ONSET OF MENSTRUATION}

The duration of vaginal blood loss after abortion is shown in table V; all patients had stopped losing blood within six weeks. Three patients required readmission and curettage for excessive vaginal bleeding. One underwent evacuation for incomplete expulsion at the time of abortion and the other two were considered to have aborted completely. In each case small amounts of decidual tissue or secretory endometrium only were recovered. There was no apparent association between the duration of vaginal bleeding and either gestation at time of abortion or route of prostaglandin administration or the use of surgical evacuation. The interval before menstruation was re-established is shown in table $\mathrm{V}$ also. Of 115 patients who had menstruated by the time of the follow-up examination 77 stated the loss was similar to that experienced before pregnancy, 21 considered the loss heavier, and 17 considered the loss reduced. Again there was no apparent relation to the route of administration, the dose of prostalgandin given, or the performance of surgical evacuation.

\section{COMPLICATIONS}

One patient, a 22-year-old girl who had had three children and three miscarriages (one spontaneous, two therapeutic), was treated at 16 weeks with extra-amniotic PGE $_{2}$. During the contractile phase she bled an estimated $800 \mathrm{ml}$ and was transfused. Complete expulsion occurred after eight and a half hours. An intrauterine contraceptive device, inserted after abortion, fell out after three days. The patient was admitted two weeks later with lower abdominal pain and a pelvic mass. Laparotomy at that time showed bilateral pyosalpinges which were left undisturbed. With antibiotics her postoperative recovery was uneventful. No pelvic disease was detected in any other patient. Retroversion of the uterus was recorded in $22 \%$ of patients.

Five patients complained of either breast soreness or lactation but they did not need treatment. Direct questioning about these symptoms has subsequently been instituted and suggests they have been under reported. This is being reassessed.

Lethargy and depression were experienced by four patients, one of whcm was severely depressed and withdrawn before abortion. She was transferred to a psychiatric unit after termination and was discharged two weeks later much improved.

Four patients had cystitis and one a vaginal discharge treated by their general practitioner. Two patients had abdominal pains during the first two weeks after discharge which needed no specific treatment. One patient was admitted to a surgical unit with acute appendicitis four weeks after abortion.

TABLE VI-Methods of Contraception Before and After Abortion in 143 Patients

\begin{tabular}{l|c|c}
\hline & $\begin{array}{c}\text { No. (\%) using } \\
\text { Contraception } \\
\text { Before } \\
\text { Abortion }\end{array}$ & $\begin{array}{c}\text { No. (\%) using } \\
\text { Contraception } \\
\text { After } \\
\text { Abortion }\end{array}$ \\
\hline No contraception & $97(67 \cdot 8)$ & $19(13 \cdot 3)$ \\
Oral contraceptive & $13(9 \cdot 1)$ & $78(5 \cdot-6)$ \\
I.U.C.D. & $7(4 \cdot 9)$ & $12(8 \cdot 4)$ \\
Diaphragm & $3(2 \cdot 1)$ & $1(0 \cdot 7)$ \\
Sheath & $19(13 \cdot)$ & $2(1 \cdot 4)$ \\
Coitus interruptus & $3(2 \cdot 1)$ & $3(2.1)$ \\
Vasectomy & $1(0 \cdot 7)$ & $8(5 \cdot 6)$ \\
Tubal ligation & & $12(8-4)$ \\
Undecided & & $\mathbf{8}(5 \cdot 6)$ \\
\hline
\end{tabular}

I.U.C.D. = Intrauterine contraceptive device.

\section{CONTRACEPTION}

The contraceptive methods used before and after abortion are shown in table VI. Four patients were sterilized immediately after abortion and eight others were sterilized before follow up or were awaiting admission for tubal ligation. Appointments at their local family planning clinic were made for all patients who were undecided about future contraception.

\section{Discussion}

Immediate and short-term morbidity after abortion has previously been shown to depend upon a patient's physical and socioeconomic status, duration of pregnancy, technique used, and coincident surgery at the time of abortion. The administration of general anaesthesia, the skill of the operator, and the time taken to abort with pharmacological methods are also relevant.

All patients in the study group (626) were from the Oxford catchment area, and almost all were in the second trimester of pregnancy (13 or more weeks). Comparison with data from the Registrar General's Statistical Review of England and Wales for 1971, Supplement on Abortion (1973) indicated to what extent our patients were nationally representative. In our study $10 \cdot 1 \%$ were aged less than 16 years, and $30.8 \%$ were $16-19$ years; none were more than 45 years of age. This compares with the Registrar General's figures for 1971 of $3 \cdot 1 \%, 22 \cdot 6 \%$, and $0.5 \%$ respectively for patients of 13 or more week's gestation. Though no statistical significance may be attached to the difference this may represent a greater willingness to refer young patients in the middle trimester for abortion when prostaglandin therapy is available. The distribution for other age groups shown in table I was very similar to that in the Registrar General's figures. The proportion of unmarried patients in this survey $(61.2 \%)$ also differed from the national figures $(51.7 \%)$ for second trimester patients. The social status of patients was not directly analysed but was probably similar to that of the group of more than 1,000 women from the same catchment area examined by Stallworthy et al. (1971). Their findings are comparable with the Registrar General's figures for 1971 (Registrar General, 1973). The distribution of parity was almost identical to that in the Registrar General's figures though the latter embraced patients from all gestational ages.

Results in the present study should be compared cautiously with those of other series because of variation in the criteria of morbidity and differences in the percentage of patients undergoing concomitant sterilization $(2.4 \%$ in this series compared with $37.6 \%$ in the Registrar General's review for patients of similar gestation).

The degree of haemorrhage has been thought to depend upon the duration of pregnancy. Thus, while the overall incidence of haemorrhage in first trimester abortions has been variously estimated at $0.06 \%$ to $10 \%$ (Stallworthy et al., 1971; Glenc, 1974) other studies have additionally shown that there can be a twofold to tenfold increase after 10 weeks gestation. (Stallworthy et al., 1971; Loung et al., 1971). In our series, however, there was no conclusive evidence of an increased incidence of haemorrhage with advancing gestation in the second trimester. Haemorrhage of more than $500 \mathrm{ml}$ occurred in $6.1 \%$ of our patients, which compares with the $4 \%$ of Stewart and Goldstein (1972) and the $18.6 \%$ of Stallworthy et al. (1971) in second trimester abortions using pharmacological means. Ballard and Ballard (1971), however, reported a $1.7 \%$ incidence 
of haemorrhage in second trimester saline-induced abortions.

Cervical laceration involving only the external os was observed in three patients in this series $(0.5 \%)$ compared with $1.5 \%$ in second trimester patients in the series of Stallworthy et al. (1971). No cervicovaginal fistulae occurred though this has been reported after intra-amniotic hypertonic saline or prostaglandins (BradleyWatson et al., 1973; Wentz et al., 1973; Kajanoja et al., 1974).

No uterine rupture was observed in this series and we were unable to find any report of this complication after pharmacologically-induced abortion. This is in contrast to its acknowledged incidence in abortions carried out by dilatation and curettage or vacuum aspiration (Kerslake and Casey 1967; Loung et al., 1971; Sood, 1971; Stallworthy et al., 1971).

Comparison of the incidence of pyrexia in different series is especially difficult because definitions vary and the use of antibiotics is seldom detailed. In the present series a pyrexic episode (a temperature of $38^{\circ} \mathrm{C}$ or more on one occasion) occurred in $5.4 \%$ of patients, and a third of these were given antibiotics. A temperature of $38^{\circ} \mathrm{C}$ for more than 24 hours was recorded in $35 \%$ of second trimester patients treated with hypertonic glucose, aminocrine, or prostaglandins by Stallworthy et al. (1971), and Ballard and Ballard (1972) noted a 4.8\% incidence of pyrexia of unspecified duration in 3,500 patients terminated with intra-amniotic hypertonic saline. Stewart and Goldstein (1972) have shown that pyrexia $\left(38^{\circ} \mathrm{C}\right.$ or more for at least 12 hours) is dependent on the time taken to achieve abortion, occurring in $6 \%$ of patients who take up to 24 hours to abort and in $42 \%$ of those who take more than 72 hours to abort.

Because of improved treatment and fewer surgical evacuations the length of stay in hospital was much reduced during the last eight months of the study period. Altogether $90 \%$ of patients were discharged within 48 hours during this time compared with $70 \%$ in the preceding study period. In terms of turnover of beds and its acceptability to patients this is very desirable. Comparison of our results with those of other studies is difficult because of inadequate detail but Loung et al. (1971) reported that in 1,000 vacuum aspiration terminations $(79 \%$ of them performed in first trimester) $89 \%$ patients stayed in hospital less than 48 hours. The incidence of tubal ligation in our series and theirs was similar. The Registrar General's figures (Registrar General, 1973) show that only about $30 \%$ of all patients aborted in N.H.S. institutions in 1971 were discharged within two days, but $27 \%$ of these patients were concomitantly sterilized.

Overall, our incidence of operative morbidity was similar to that reported for first trimester abortion and better than that in most series of second trimester abortions.

Complications after discharge from hospital have generally been less well reported than immediate operative morbidity. Significant illness in the early recovery period was rarely observed in our patients though three required readmission for excessive vaginal bleeding. One patient developed pelvic sepsis. The incidence of genital tract infection was similar to the $1 \%-2 \%$ reported by Jurukovski and Sukarov (1971) and Glenc (1974) after first trimester surgical abortion.

The duration of bleeding after abortion was longer than the three to five days reported by Beric et al. (1973) after vacuum aspiration. In most patients menstruation had begun again within six weeks of abortion, and only $18 \%$ considered the first loss heavier than normal.

Contraceptive follow up of patients after abortion is of paramount importance and should be regarded as part of the management of each case. Our results and those in a similar group investigated 18 months after abortion (MacKenzie and Hillier, unpublished data) broadly compare with the recent findings of Beard et al. (1974).

There are many cogent reasons for advising that therapeutic abortion is best performed as early as possible in pregnancy. Nevertheless, the present results indicate that the operative and early morbidity associated with second trimester abortion using intra- or extra-amniotic prostaglandins is comparable with that reported for first trimester termination by vacuum aspiration and is considerably less than in most studies of second trimester abortion using other methods (Department of Health and Social Security, 1974). This is possibly a reflection of the shorter induction-abortion interval achieved compared with other pharmacological agents. Careful attention to the technique of administration and care of the patient in a specialized unit may also have contributed to the low level of observed morbidity.

We thank Professor Martin Vessey and Professor A. C. Turnbull for helpful criticism and advice in preparing this paper, Sister Mary Tuckwell and staff for expert patient care, and Miss N. J. BremnerMilne for secretarial help.

This work was supported by grants from the Agency for International Development (No. csd 2837) and the World Health Organization. Prostaglandins were a gift from the Upjohn Company.

\section{References}

Ballard, C. A., and Ballard, F. E. (1972). American fournal of Obstetrics and Gynecology, 114, 575

Beard, R. W., et al. (1974). British Medical fournal, 1, 418.

Beric, B. M., Kupresanin, M., and Kapor-Stanulovic, N. (1973). American Fournal of Obstetrics and Gynecology, 116, 813.

Bradley-Watson, P. J., Beard, R. J., and Craft, I. L. (1973). Fournal of Obstetrics and Gynaecology of the British Commonwealth, 80, 284.

Embrey, M. P., Hillier, K., and Mahendran, P. (1972). British Medical Fournal, 3, 146.

Embrey, M. P., Hillier, K., and Mahendran, P. (1973). Advances in Biosciences, $9,507$.

Glenc, F. (1974). American fournal of Obstetrics and Gynecology, 118, 34.

Hillier, K., and Embrey, M. P. (1972). Fournal of Obstetrics and Gynaecology, of the British Commonwealth, 79, 14.

Jurukovski, J., and Sukarov, L. (1971). International fournal of Obstetrics and Gynaecology, $9,111$.

Kajanoja, P., et al. (1974). Fournal of Obstetrics and Gynaecology of the British Commonwealth 81, 242.

Kerslake, D. M., and Casey, D. (1967). Obstetrics and Gynecology, 30, 35. Loung, K. L., Buckle, A. E. R., and Anderson, M. M. (1971). British Medical fournal, 4, 477.

MacKenzie, I. Z., Embrey, M. P., and Hillier, K. (1974). Fournal of Obstetrics and Gynaecology of the British Commonwealth, 81, 554.

Department of Health and Social Security. (1974). Report of the Committee on the Working of the Abortion Act, vol. 1, 233. London, H.M.S.O.

Sood, S. V. (1971). British Medical fournal, 4, 270.

Sood, S. V. (1971). British Medical fournal, 4, 270. (1971)

Stallworthy, J. A., Moolgaoker, A. S., and Walsh, J. J. (1971). Lancet, 2, 1245.

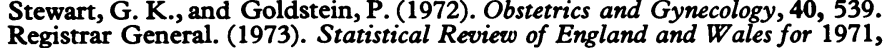
Registrar General. (1973). Statistical Reviewv of E
Supplement on Abortion. London, H.M.S.O.

Wentz, A. C., Thompson, B. H., and King, T. M. (1973). American fournal of Obstetrics and Gynecology, 115, 1107. 